\title{
WHAT IS THE IMPACT OF AFFECTIVE DISPOSITION ON 4TH-GRADE NAEP READING SCORES?
}

\author{
Christina Mollica Peterson ${ }^{1}$, Mingyuan Zhang $2 \square$ \\ 1,2 College of Education and Human Services, Central Michigan University, USA
}

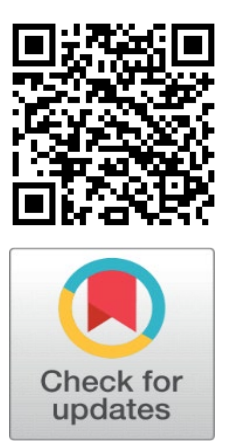

Received 16 September 2021

Accepted 14 October 2021

Published 31 October 2021

CorrespondingAuthor

Mingyuan Zhang,

zhang1m@cmich.edu

\section{DOI}

10.29121/granthaalayah.v9.i10.2021 .4330

Funding: This research received no specific grant from any funding agency in the public, commercial, or not-for-profit sectors.

Copyright: (C) 2021 The Author(s). This is an open access article distributed under the terms of the Creative Commons Attribution License, which permits unrestricted use, distribution, and reproduction in any medium, provided the original author and source are credited.

\section{ABSTRACT}

This study presented a secondary analysis of the National Assessment of Educational Progress (NAEP) dataset. The paper examined the impact of affective disposition on 2019 NAEP reading scores of fourth-grade students. In order to gain a better understanding of the impact of affective disposition on the reading achievement of fourth-grade students, this study used a quantitative descriptive research design to analyze secondary data extracted from the 2019 NAEP data set.

The results found in this study showed that students' affective disposition in the areas of making a great effort after making a mistake, continuing to work hard even when they felt like quitting, paying attention and resisting distractions, and feeling happy at school had positive impact on their 2019 NAEP reading assessments scores when the students strongly agreed with the statements. The findings may indicate that improving affective disposition in students may increase reading scores.

Keywords: NAEP; National Data; Reading Proficiency; Growth Mindset; Mindfulness; Positive Education Framework

\section{INTRODUCTION}

Reading is an important and necessary skill for students to learn in elementary school in order for them to succeed academically. While the methods of teaching and the curriculums used are important factors for students to learn to read, there are factors outside of these areas that could affect students' ability to read. These factors include students' emotional states, how they view their intelligence, how they deal with challenges and failure, and their attention skills in school. Farrington et al. (2002) referred to these as noncognitive factors and discussed how these factors impact students' progress in school. Teaching skills such as growth mindset and mindfulness as well as implementing a positive education framework could improve these noncognitive factors and improve academic skills (Dweck (2006); Neff (2003); Noble and Mcgrath (2015); Norrish et al. (2013)). If these noncognitive factors can be taught in school and if these factors have been shown to improve academic skills, it is worth exploring the current data on 4th-grade reading NAEP scores to determine if affective disposition has impacted the reading scores. 
National Assessment of Educational Progress (NAEP) has collected test scores of students in the United States in major subject areas since 1969 in order to report on what students know and to compare the achievement and performance in the subject areas from year to year (Donahue et al. (2004)). NAEP assessments differ from the assessments that states give to students. NAEP assessments are given to students in the 4th, 8th, and 12th grades. Students' scores are categorized as basic, proficient, and advanced. The scores are also used to compare achievement and performance between schools in different parts of the country. The results are reported by similar groups (geographic location, gender, race) and not as individual scores. The results are used to improve educational policies, to identify where schools need to improve, and as a benchmark for schools to set in order to have students achieve beyond that benchmark. In 4th-grade, students are assessed on two areas of reading, the context for reading and the aspect of reading. Questionnaires are also completed by students, teachers, and administrators. These questionnaires include technology use, learning in and out of the classroom, teacher training, and school characteristics (About The Nation's Report Card: NAEP, 2020).

Clark and Teravainen-Goff (2018) found that children who scored low on literacy skills also scored low on mental well-being. The authors also found that those students with high mental well-being reported enjoying reading more than those students with low mental well-being. Students with low mental wellbeing were more likely to report that they were below-average readers. Parhiala et al. (2018) found that students with low emotional well-being had lower scores in math and reading but only when they also had low school motivation.

While Clark and Teravainen-Goff (2018) found a relationship between low literacy skills and low mental wellbeing, they reported a lack of research in this area. Both studies, Clark and Teravainen-Goff (2018) and Parhiala et al. (2018), were completed in European countries and may not reflect the United States school system. There seems to be a lack of research in this area completed with schools in the United States.

The purpose of this research is to investigate the impact of affective disposition on NAEP fourth-grade reading scores. Teachers and administrators would be interested in this research because it could help them identify areas of well-being to focus on in order to improve students' reading scores. These areas could include implementing a positive education framework, instructing students and teachers about growth mindset, and teaching students and teachers to practice mindfulness. Parents would be interested in this research so that they could find programs outside of school to improve their children's well-being.

This study will focus on answering the following research questions in order to examine this relationship:

1) What impact does students' effort after making mistakes have on 4-grade NAEP reading scores?

2) What impact does students' effort even when they feel like quitting make on 4-grade NAEP reading scores?

In 2002, Farrington et al. discussed how noncognitive factors impact students' progress in school. Noncognitive factors may include students' beliefs about their intelligence, self-control, motivation, self-regulation, time management, and determination. Studies have shown that using a positive education model and addressing the needs of students' well-being can improve students' academic mindset skills (Dweck (2006); Noble and Mcgrath (2015); Norrish et al. (2013)). Mindfulness meditation programs are included in positive education programs since mindfulness meditation has been shown to reduce stress, anxiety, and burnout 
and improve self-compassion and mindfulness skills (Beauchemin et al. (2008); Hjeltnes et al. (2015); Neff (2003)).

The type of mindset students have can impact their academic performance and how they handle setbacks and failures in their coursework. Dweck $(1986,2006)$ and Elliott and Dweck (1988) identified that when students have a fixed mindset they believe that intelligence is set and cannot be changed or improved. Students with fixed mindsets focus on performance goals and that they have to perform well in order to prove their intelligence. Students with a growth mindset learn from their failures and believe that intelligence is a changeable state. These students focus on achievement goals. They believe that with hard work and perseverance, goals can be achieved.

Mindfulness is a skill being taught more frequently in schools due to the benefits that practicing can have on students' well-being and academic skills. In a mindfulness curriculum created for schools, the lessons cover many different areas: self-regulation of attention, awareness of thoughts and emotions, compassion for self and others, and gratitude (Ackerman (2018; Bishop et al. (2004); Fredrickson, (2009)). In the area of self-regulation of attention, students are taught to focus all of their attention on one area. Focusing on their breath is the most common area and typically what students are taught first. Students may also be taught to focus on sounds, sights, emotions, thoughts, and feelings in their bodies. Teaching students to focus on these different areas improves their attention and awareness of what is going on in their minds and bodies (Bishop et al. (2004)). The continued practice of mindfulness integrates the brain which enhances self-regulation (Siegel (2016)).

Farrington et al. (2012) reported on the importance of schools focusing on students' noncognitive skills (beliefs about their intelligence, self-control, motivation, self-regulation, time management, and determination). Noncognitive skills interact with academic skills and content knowledge and improve students' ability to learn and without the interaction of all three areas that ability is decreased. Noncognitive factors are outside of the content knowledge and academic skills that students possess and are not measured by IQ tests or school academic tests.

Our theoretical framework for this research adopts a scientific inquiry-based approach. The framework was described in great details in The Impact of Conversations on Fourth Grade Reading Performance - What NAEP Data Explorer Tells? (Bond and Zhang (2017)). In summary, the research methods combined the inquiry process with scientific knowledge, reasoning, and critical thinking. We started with an extensive exploration of the dataset, and that led to the designing of the research questions. The research questions further guided us to mine the data with great in-depth.

\section{RESEARCH METHODS}

The National Assessment of Educational Progress (NAEP) is the largest nationally representative and continuing assessment of what America's students know and can do in various subject areas. NAEP assessments are administered uniformly with the results serving as a common metric for all states and selected urban districts (NCES (2020)). NAEP data provide a picture of student academic progress over time as the assessment stays essentially the same from year to year (NCES (2020)). 


\section{Participants and Sampling}

NCES (2021a) reported that every two years students in grade 4 are given the National Assessment of Education Progress (NAEP) reading assessment. Students are asked to read grade-appropriate materials and asked comprehension questions about the materials. The results show students' knowledge of reading, reading skills, and performance. In 2019, the reading assessment was administered to close to 150,600 students in grade 4.

\section{NAEP Sampling and Data Collection}

A multistage sampling design that sampled students from select schools with selected geographic areas across the country was used for sampling for the 4thgrade reading assessment (Klecker (2014)). A sample of students in 4th-grade, for each assessment cycle, within both public and private schools throughout the United States (and sometimes specified territories and possession) was selected for assessment.

\section{Public School Selection in State Assessment Years}

The sample selection of public- school students nationwide for their state assessment involved a complex multistage sampling design with the following stages:

- Select public schools within the designated areas,

- Select students in the relevant grade within the designated schools, and

- Allocate selected students as assessment subjects ("NAEP - Sample", 2018).

\section{Data Analysis}

NAEP data explorer. The NAEP Data Explorer is an online, analysis tool found at https://nces.ed.gov/nationsreportcard/data/ that allowed for descriptive analysis of the assessment data. The Data Explorer provides national and state results in many subject areas including reading, math, writing, and science (NCES (2021b)). Since 1990, results have been produced for the nation, participating states, and other jurisdictions, and since 2002 for selected urban districts (on a trial basis). The NAEP Data Explorer was used to analyze the 2019 NAEP fourth-grade reading assessment composite average scale scores and standard deviations were selected for the examinations. The selected variables included "student factors" with a subcategory of "affective disposition." The four coded questions selected through Data Explorer (NCES (2021b)) were:

1) How much does each of the following statements describe a person like you? I try very hard even after making mistakes. (student-reported) (Options: Not at all like me, A little bit like me, Somewhat like me, Quite a bit like me, Very much like me). [ID: B034902]

2) How much does each of the following statements describe a person like you? I keep working hard even when I feel like quitting. (studentreported) (Options: Not at all like me, A little bit like me, Somewhat like me, Quite a bit like me, Very much like me). [ID: B034903] 
Descriptive tables and tests of statistically significant differences (alpha set a priori at 0.001 because of the large $n$ of the sample) were calculated and presented by Data Explorer (NCES (2021b)). In several instances, the tables were re-formatted without editing the data in the tables. Cohen's $d$ effect sizes (Cohen (1988)) were calculated by using an online effect size calculator found at http://www.uccs.edu/ lbecker/ (Becker (2000)). The definition of Cohen's $d$ effect size is a relevant effect size between two means. Cohen's $d$ is used frequently in meta-analysis and accompanies the reporting of a t-test and ANOVA results (Mcleod (2019)).

\section{RESULTS}

In this section, the four NAEP questions regarding different areas of 4th-grade students' affective disposition and the impact of those areas on the 2019 student reading achievement scores will be presented by showing the average scores and percentages of different groups in each variable. The results of independent t-tests with an alpha level of 0.05 will be reported and analyzed in association with the literature review.

\section{Data Analysis}

The average scale score, nationwide, for $100 \%$ of the 4 th-grade students on the 2019 NAEP Reading Assessment was 210 (scale-range 0-500) with a standard deviation of 39. Differences in scores by questions are presented in tables throughout the results section. Because NAEP's Data Explorer does not include the number of students $(\mathrm{N})$, the expected value $(\mathrm{N})$ is absent in the table below and in the other tables in the Results and Data Analysis (Klecker, 2014; NAEP, 2018). The results pertaining to each research question (RQ) are presented here individually.

$R Q$ \#1: How much does each of the following statements describe a person like you? I try very hard even after making mistakes.

Table 1 shows the 2019 reading scale score and standard deviations for fourthgrade national-public school students based on their reported frequency of make great effort even after making mistakes.

\begin{tabular}{|c|c|c|c|c|}
\hline Year & Jurisdiction & $\begin{array}{l}\text { Make great effort even after } \\
\text { making mistakes }\end{array}$ & $\begin{array}{l}\text { Average scale } \\
\text { score }\end{array}$ & $\begin{array}{l}\text { Standard } \\
\text { deviation }\end{array}$ \\
\hline \multirow[t]{5}{*}{2019} & \multirow[t]{5}{*}{ National public } & Not at all like me & 186 & 41 \\
\hline & & A little bit like me & 200 & 42 \\
\hline & & Somewhat like me & 218 & 39 \\
\hline & & Quite a bit like me & 228 & 35 \\
\hline & & Very much like me & 223 & 35 \\
\hline
\end{tabular}

NOTE: Some apparent differences between estimates may not be statistically significant.

SOURCE: U.S. Department of Education, Institute of Education Sciences, National Center for Education Statistics, National Assessment of Educational Progress (NAEP), 2019 Reading Assessment.

In Table 1, the average reading comprehension scores for making a great effort even after making mistakes are presented. The average score of the 4th-grade students who reported "not at all like me" to making a great effort after making mistakes was $186(\mathrm{SD}=41)$. The average scale score of students who reported "a 
little bit like me" to making a great effort after making mistakes was $200(\mathrm{SD}=42)$. The average scale score of students who reported "somewhat like me" was 218 $(\mathrm{SD}=39)$. The average scale score of students who reported "quite a bit like me" was $228(\mathrm{SD}=35)$. The average scale score of students who reported "very much like me" was $223(\mathrm{SD}=35)$.

The differences in means and independent $t$-test results for the frequency of make great effort even after making mistakes are shown in Table 2.

Table 2 Difference in Average Scale Scores Between Variables, For Make Great Effort Even After Making Mistakes [B034902]

\begin{tabular}{|c|c|c|c|c|c|c|}
\hline & $\begin{array}{l}\text { Not at all } \\
\text { like } \\
(186)\end{array}$ & $\begin{array}{ll}\text { A little bit } \\
\text { like } & \text { me } \\
(200) & \end{array}$ & $\begin{array}{l}\text { Somewhat like } \\
\text { me (218) }\end{array}$ & $\begin{array}{lll}\text { Quite } & \text { a } & \text { bit } \\
\text { like } & \text { me } \\
(228) & \end{array}$ & $\begin{array}{l}\text { Very } \\
\text { like } \\
(223)\end{array}$ & $\begin{array}{r}\text { much } \\
\text { me }\end{array}$ \\
\hline \multicolumn{7}{|l|}{$\begin{array}{l}\text { Not at all like } \\
\text { me }\end{array}$} \\
\hline $\begin{array}{l}\text { A little bit like } \\
\text { me }\end{array}$ & $\begin{array}{l}> \\
\text { Diff = } 14 \\
\text { P-value = } \\
0.0000 \\
\text { Family size = } \\
10\end{array}$ & & & & & \\
\hline $\begin{array}{l}\text { Somewhat } \\
\text { like me }\end{array}$ & $\begin{array}{l}> \\
\text { Diff = } 32 \\
\text { P-value = } \\
0.0000 \\
\text { Family size = } \\
10\end{array}$ & $\begin{array}{l}> \\
\text { Diff = } 18 \\
\text { P-value = } \\
0.0000 \\
\text { Family size = } \\
10\end{array}$ & & & & \\
\hline $\begin{array}{l}\text { Quite a bit } \\
\text { like me }\end{array}$ & $\begin{array}{l}> \\
\text { Diff = } 43 \\
\text { P-value = } \\
0.0000 \\
\text { Family size = } \\
10\end{array}$ & $\begin{array}{l}> \\
\text { Diff = } 28 \\
\text { P-value = } \\
0.0000 \\
\text { Family size = } \\
10\end{array}$ & $\begin{array}{l}> \\
\text { Diff } \quad=10 \\
\text { P-value }=0.0000 \\
\text { Family size }=10\end{array}$ & & & \\
\hline $\begin{array}{l}\text { Very much } \\
\text { like me }\end{array}$ & $\begin{array}{l}> \\
\text { Diff = } 37 \\
\text { P-value = } \\
0.0000 \\
\text { Family size = } \\
10\end{array}$ & $\begin{array}{l}> \\
\text { Diff = } 23 \\
\text { P-value = } \\
0.0000 \\
\text { Family size = } \\
10\end{array}$ & $\begin{array}{l}> \\
\text { Diff }=5 \\
\text { P-value }=0.0000 \\
\text { Family size }=10\end{array}$ & $\begin{array}{l}< \\
\text { Diff = } \\
\text { P-value = } \\
0.0000 \\
\text { Family size = } \\
10\end{array}$ & & \\
\hline \multicolumn{7}{|l|}{ LEGEND: } \\
\hline$<$ & \multicolumn{6}{|c|}{ Significantly lower. } \\
\hline$>$ & \multicolumn{6}{|c|}{ Significantly higher. } \\
\hline $\mathrm{x}$ & \multicolumn{6}{|c|}{ No significant difference. } \\
\hline
\end{tabular}

NOTE: Within jurisdiction comparisons on any given year are dependent with an alpha level of 0.05.

SOURCE: U.S. Department of Education, Institute of Education Sciences, National Center for Education Statistics, National Assessment of Educational Progress (NAEP), 2019 Reading Assessment

Table 2, created by NAEP Data Explorer ("NCES", 2021b), presents mean differences and the results of multiple independent t-tests. NAEP Data Explorer analyses had alpha set at 0.05 . The average scale score of students who reported "very much like me" to making a great effort after making a mistake $(\mathrm{M}=223$; $\mathrm{SD}=$ 35) was significantly ( $p<0.001)$ higher than the average scale scores of students who reported "not at all like me" to making a great effort after making a mistake (M= $186 ; \mathrm{SD}=41$ ). The average scale score of students who reported "quite a bit like me" to making a great effort after making a mistake $(M=228 ; S D=35)$ was significantly ( $\mathrm{p}<0.001)$ higher than the average scale scores of students who reported "not at all 
like me" to making a great effort after making a mistake $(M=186 ; S D=41)$. The average scale score of students who reported "somewhat like me" to make a great effort after making a mistake $(M=218 ; S D=39)$ was significantly $(p<0.001)$ higher than the average scale scores of students who reported "not at all like me" to making a great effort after making a mistake $(M=186 ; S D=41)$. The average scale score of students who reported "a little bit like me" to making a great effort after making a mistake $(M=200 ; S D=42)$ was significantly $(p<0.001)$ higher than the average scale scores of students who reported "not at all like me" to making a great effort after making a mistake $(M=186 ; \mathrm{SD}=41)$.

The average scale score of students who reported "very much like me" to making a great effort after making a mistake $(M=223$; $S D=35)$ was significantly ( $p$ $<0.001$ ) higher than the average scale scores of students who reported "a little bit like me" to making a great effort after making a mistake $(M=200 ; S D=42)$. The average scale score of students who reported "very much like me" to making a great effort after making a mistake $(M=223$; $S D=35)$ was significantly $(p<0.001)$ higher than the average scale scores of students who reported "somewhat like me" to making a great effort after making a mistake $(M=218 ; S D=39)$. The average scale score of students who reported "quite a bit like me" to making a great effort after making a mistake $(M=228 ; S D=35)$ was significantly $(p<0.001)$ higher than the average scale scores of students who reported "a little bit like me" to making a great effort after making a mistake $(M=200 ; S D=42)$. The average scale score of students who reported "quite a bit like me" to making a great effort after making a mistake $(M=228 ; S D=35)$ was significantly $(p<0.001)$ higher than the average scale scores of students who reported "somewhat like me" to making a great effort after making a mistake $(M=218 ; S D=39)$. The average scale score of students who reported "somewhat like me" to make a great effort after making a mistake (M=218; $\mathrm{SD}=39)$ was significantly $(\mathrm{p}<0.001)$ higher than the average scale scores of students who reported "a little bit like me" to making a great effort after making a mistake (M= 200; $\mathrm{SD}=42$ ).

Table 3 shows the Cohen's $d$ effect size of the significant mean score differences for make a great effort even after making mistakes.

\begin{tabular}{lllll}
\hline \multicolumn{2}{l}{$\begin{array}{l}\text { Table } 3 \text { Effect Sizes of Differences in Scores When Students } \\
\text { Making Mistakes [B034902] }\end{array}$} & \multicolumn{2}{l}{ Means (SD) } & Cohen's $\boldsymbol{d}$ \\
\hline Frequencies & Means (SD) & Frequencies & $186(41)$ & 0.34 \\
\hline A little bit like me & $200(42)$ & Not at all like me & $186(41)$ & 0.80 \\
\hline Somewhat like me & $218(39)$ & Not at all like me & $186(41)$ & 1.10 \\
\hline $\begin{array}{l}\text { Quite a bit like me } \\
\text { Very much like me }\end{array}$ & $228(35)$ & Not at all like me & $186(41)$ & 0.97 \\
\hline Somewhat like me & $218(39)$ & Not at all like me & $200(42)$ & 0.44 \\
\hline Quite a bit like me & $228(35)$ & A little bit like me & $218(39)$ & 0.27 \\
\hline Quite a bit like me & $228(35)$ & A little bit like me & $200(42)$ & 0.72 \\
\hline Very much like me & $223(35)$ & A little bit like me & $200(42)$ & 0.59 \\
\hline Very much like me & $223(35)$ & Somewhat like me & $218(39)$ & 0.13 \\
\hline Quite a bit like me & $228(35)$ & Very much like me & $223(35)$ & 0.14
\end{tabular}

Effect size measures are the common currency of meta-analysis studies that summarize the findings from a specific area of research (Becker (2000 b). An effect 
size of 0.2 is considered small, an effect size of 0.5 is medium, and an effect size of 0.8 is large (Mcleod (2019)). In Table 4, the effect size of make a great effort even after making a mistake is presented. The Cohen's $d$ effect size of the difference between the average scale score of students who reported "very much like me" to make a great effort even after making a mistake and that of the students who replied "quite a bit like me", "somewhat like me", "a little bit like me", and "not at all like me" were respectively $d=0.14, d=0.13, d=0.59$, and $d=0.97$. The Cohen's $d$ effect size of the difference between the average scale score of students who reported "quite a bit like me" to make a great effort even after making a mistake and that of the students who replied "somewhat like me", "a little bit like me" and "not at all like me" were respectively $d=0.27, d=0.72$, and $d=1.10$. The Cohen's $d$ effect size of the difference between the average scale score of students who reported "somewhat like me" to make a great effort even after making a mistake and that of the students who replied "a little bit like me" and "not at all like me" were respectively $d=0.44$ and $d=0.80$. The Cohen's $d$ effect size of the difference between the average scale score of students who reported "a little bit like me" and "not at all like me" was $d=0.34$.

The Cohen's $d$ effect sizes were large between "very much like me" and "not at all like me" $(d=0.97)$, between "quite a bit like me" and "not at all like me" $(d=1.10)$, and between "somewhat like me" and "not at all like me" $(d=0.80)$. The Cohen's $d$ effect sizes were medium between "very much like me" and "a little bit like me" $(d=0.59)$ and between "quite a bit like me" and "a little bit like me" $(d=0.72)$. The remaining effect sizes were small.

$R Q \# 2$ - How much does each of the following statements describe a person like you? I keep working hard even when I feel like quitting.

Table 4 shows the 2019 reading scale score and standard deviation for fourthgrade national-public students based on their reported frequency of continuing to work hard even when they feel like quitting.

Table 4 Average scale scores and standard deviations for 4th-grade reading, by frequency of I keep working hard even when I feel like quitting. [ID: B034903]

\begin{tabular}{|lllll}
\hline Year & Jurisdiction & $\begin{array}{c}\text { Keep working hard even } \\
\text { when I feel like quitting }\end{array}$ & $\begin{array}{c}\text { Average scale } \\
\text { score }\end{array}$ & $\begin{array}{c}\text { Standard } \\
\text { deviation }\end{array}$ \\
\hline \multirow{2}{*}{ National public } & Not at all like me & 195 & 40 \\
\cline { 2 - 4 } & A little bit like me & 211 & 41 \\
& Somewhat like me & 220 & 41 \\
& Quite a bit like me & 228 & 36 \\
& Very much like me & 222 & 35
\end{tabular}

NOTE: Some apparent differences between estimates may not be statistically significant.

SOURCE: U.S. Department of Education, Institute of Education Sciences, National Center for Education Statistics, National Assessment of Educational Progress (NAEP), 2019 Reading Assessment.

In Table 4, the average reading comprehension scores for keep working hard even when I feel like quitting are presented. The average score of the 4th-grade students who reported "not at all like me" to keep working hard even when I feel like quitting was $195(\mathrm{SD}=40)$. The average scale score of students who reported "a little bit like me" to keep working hard even when I feel like quitting was 211 (SD= 41). The average scale score of students who reported "somewhat like me" was 220 $(\mathrm{SD}=41)$. The average scale score of students who reported "quite a bit like me" was $228(\mathrm{SD}=36)$. The average scale score of students who reported "very much like me" was $222(\mathrm{SD}=35)$. 
The differences in means and independent $t$-test results for the frequency of keep working hard even when I feel like quitting are shown in Table 5.

\begin{tabular}{|c|c|c|c|c|c|c|}
\hline & $\begin{array}{l}\text { Not at all } \\
\text { like } \\
(195)\end{array}$ & $\begin{array}{ll}\text { A little bit } \\
\text { like } & \text { me } \\
(211) & \end{array}$ & $\begin{array}{l}\text { Somewhat like } \\
\text { me }(220)\end{array}$ & $\begin{array}{lll}\text { Quite } & \text { a } & \text { bit } \\
\text { like } & \text { me } \\
(228) & \end{array}$ & $\begin{array}{l}\text { Very } \\
\text { like } \\
(222)\end{array}$ & $\begin{array}{r}\text { much } \\
\text { me }\end{array}$ \\
\hline \multicolumn{7}{|l|}{$\begin{array}{l}\text { Not at all like } \\
\text { me }\end{array}$} \\
\hline $\begin{array}{l}\text { A little bit like } \\
\text { me }\end{array}$ & $\begin{array}{l}> \\
\text { Diff = } 17 \\
\text { P-value = } \\
0.0000 \\
\text { Family size = } \\
10\end{array}$ & & & & & \\
\hline $\begin{array}{l}\text { Somewhat } \\
\text { like me }\end{array}$ & $\begin{array}{l}> \\
\text { Diff = } 25 \\
\text { P-value = } \\
0.0000 \\
\text { Family size = } \\
10\end{array}$ & $\begin{array}{l}> \\
\text { Diff = } 9 \\
\text { P-value = } \\
0.0000 \\
\text { Family size = } \\
10\end{array}$ & & & & \\
\hline $\begin{array}{l}\text { Quite a bit } \\
\text { like me }\end{array}$ & $\begin{array}{l}> \\
\text { Diff = } 34 \\
\text { P-value = } \\
0.0000 \\
\text { Family size = } \\
10\end{array}$ & $\begin{array}{l}> \\
\text { Diff = } 17 \\
\text { P-value = } \\
0.0000 \\
\text { Family size = } \\
10\end{array}$ & $\begin{array}{l}> \\
\text { Diff } \quad=\quad 8 \\
\text { P-value }=0.0000 \\
\text { Family size }=10\end{array}$ & & & \\
\hline $\begin{array}{l}\text { Very much } \\
\text { like me }\end{array}$ & $\begin{array}{l}> \\
\text { Diff = } 27 \\
\text { P-value = } \\
0.0000 \\
\text { Family size = } \\
10\end{array}$ & $\begin{array}{l}> \\
\text { Diff = } 11 \\
\text { P-value = } \\
0.0000 \\
\text { Family size = } \\
10\end{array}$ & $\begin{array}{l}> \\
\text { Diff }=2 \\
\text { P-value }=0.0021 \\
\text { Family size }=10\end{array}$ & $\begin{array}{l}< \\
\text { Diff = } \\
\text { P-value = } \\
0.0000 \\
\text { Family size = } \\
10\end{array}$ & & \\
\hline \multicolumn{7}{|l|}{ LEGEND: } \\
\hline$<$ & \multicolumn{6}{|c|}{ Significantly lower. } \\
\hline$>$ & \multicolumn{6}{|c|}{ Significantly higher. } \\
\hline $\mathrm{x}$ & \multicolumn{6}{|c|}{ No significant difference. } \\
\hline
\end{tabular}

NOTE: Within jurisdiction comparisons on any given year are dependent with an alpha level of 0.05.

SOURCE: U.S. Department of Education, Institute of Education Sciences, National Center for Education Statistics, National Assessment of Educational Progress (NAEP), 2019 Reading Assessment

Table 5, created by NAEP Data Explorer ("NCES", 2021b), presents mean differences and the results of multiple independent t-tests. NAEP Data Explorer analyses had alpha set at 0.05 . The average scale score of students who reported "very much like me" to keep working hard even when I feel like quitting was $(M=222 ; S D=35)$ was significantly $(p<0.001)$ higher than the average scale scores of students who reported "not at all like me" to keep working hard even when I feel like quitting $(M=195 ; S D=40)$. The average scale score of students who reported "quite a bit like me" to keep working hard even when I feel like quitting ( $M=228$; $\mathrm{SD}=36)$ was significantly $(\mathrm{p}<0.001)$ higher than the average scale scores of students who reported "not at all like me" to making a great effort after making a mistake (M= 195; SD=40). The average scale score of students who reported "somewhat like me" to keep working hard even when I feel like quitting $(M=220 ; S D=41)$ was 
significantly $(\mathrm{p}<0.001)$ higher than the average scale scores of students who reported "not at all like me" to making a great effort after making a mistake ( $M=195$; $\mathrm{SD}=40$ ). The average scale score of students who reported "a little bit like me" to keep working hard even when I feel like quitting $(M=211 ; S D=41)$ was significantly $(\mathrm{p}<0.001)$ higher than the average scale scores of students who reported "not at all like me" to keep working hard even when I feel like quitting ( $M=195 ; S D=40)$.

The average scale score of students who reported "very much like me" to keep working hard even when I feel like quitting $(M=222 ; S D=35)$ was significantly ( $p$ $<0.001$ ) higher than the average scale scores of students who reported "a little bit like me" to keep working hard even when I feel like quitting $(M=211 ; S D=41)$. The average scale score of students who reported "very much like me" to keep working hard even when I feel like quitting $(M=222 ; S D=35)$ was significantly $(\mathrm{p}<0.001)$ higher than the average scale scores of students who reported "somewhat like me" to keep working hard even when I feel like quitting ( $M=220 ; S D=41)$. The average scale score of students who reported "quite a bit like me" to keep working hard even when I feel like quitting $(M=228 ; S D=36)$ was significantly $(p<0.001)$ higher than the average scale scores of students who reported "a little bit like me" to keep working hard even when I feel like quitting $(M=211 ; \mathrm{SD}=41)$. The average scale score of students who reported "quite a bit like me" to keep working hard even when I feel like quitting $(M=228 ; S D=36)$ was significantly $(p<0.001)$ higher than the average scale scores of students who reported "somewhat like me" to keep working hard even when I feel like quitting $(M=220$; $S D=41)$. The average scale score of students who reported "somewhat like me" to keep working hard even when I feel like quitting $(M=220 ; S D=41)$ was significantly $(\mathrm{p}<0.001)$ higher than the average scale scores of students who reported "a little bit like me" to keep working hard even when I feel like quitting $(M=21 ; S D=41)$.

Table 6 shows the Cohen's $d$ effect size of the significant mean score differences for keep working hard even when I feel like quitting.

Table 6 Effect Sizes of Significant Mean Score Differences when students keep working hard even when I feel like quitting [ID: B034903]

\begin{tabular}{|ccccc}
\hline Frequencies & Means (SD) & Frequencies & Means (SD) & Cohen's $d$ \\
\hline A little bit like me & $211(41)$ & Not like me & $194(40)$ & 0.40 \\
\hline Somewhat like me & $220(41)$ & Not like me & $194(40)$ & 0.62 \\
Quite a bit like me & $228(36)$ & Not like me & $194(40)$ & 0.87 \\
Very much like me & $222(35)$ & Not like me & $194(40)$ & 0.72 \\
Somewhat like me & $220(41)$ & A little bit like me & $211(41)$ & 0.22 \\
Quite a bit like me & $228(36)$ & A little bit like me & $211(41)$ & 0.44 \\
Quite a bit like me & $228(36)$ & Somewhat like me & $220(41)$ & 0.21 \\
Very much like me & $222(35)$ & A little bit like me & $211(41)$ & 0.28 \\
Very much like me & $222(35)$ & Somewhat like me & $220(41)$ & 0.05 \\
Very much like me & $222(35)$ & Quite a bit like me & $228(36)$ & 0.17
\end{tabular}

Effect size measures are the common currency of meta-analysis studies that summarize the findings from a specific area of research (Becker (2000)). An effect size of 0.2 is considered small, an effect size of 0.5 is medium, and an effect size of 0.8 is large (Mcleod (2019)). In Table 6, the effect size of keep working hard even when I feel like quitting is presented. The Cohen's $d$ effect size of the difference between the average scale score of students who reported "very much like me" to keep working hard even when I feel like quitting and that of the students who replied "quite a bit like me", "somewhat like me", "a little bit like me", and "not at all like me" were respectively $d=0.17, d=0.05, d=0.28$, and $d=0.72$. The Cohen's $d$ effect 
size of the difference between the average scale score of students who reported "quite a bit like me" to keep working hard even when I feel like quitting and that of the students who replied "somewhat like me", "a little bit like me" and "not at all like me" were respectively $d=0.22, d=0.44$, and $d=0.87$. The Cohen's $d$ effect size of the difference between the average scale score of students who reported "somewhat like me" to keep working hard even when I feel like quitting and that of the students who replied "a little bit like me" and "not at all like me" were respectively $d=0.22$ and $d=0.62$. The Cohen's $d$ effect size of the difference between the average scale score of students who reported "a little bit like me" and "not at all like me" was $d=0.40$.

The Cohen's $d$ effect size was large between "quite a bit like me" and "not at all like me" $(d=0.87)$. The Cohen's $d$ effect sizes were medium $(<0.8)$ between "very much like me" and "not at all like me" $(d=0.72)$ and "somewhat like me" and "not at all like me" $(d=0.62)$. The remaining effect sizes were small $(<0.5)$.

\section{DISCUSSION}

This study explored the 2019 NAEP student reading achievement scores for 4th-grade students and how different areas of affective disposition impacted those scores. Descriptive statistics were used to analyze the data. The use of descriptive statistics helps identify trends in the data, gives insight into how scores might be varied, and shows how the scores compare to each other (Creswell and Guetterman (2019)). The selected research questions reported on the reading scores of students who reported how much effort they made after making mistakes, how much the students kept working hard even when they felt like quitting, how often they paid attention and resisted distractions, and how often they felt happy at school.

\section{Make Great Effort Even After Making Mistakes}

The results from this study found that students who responded that they make great effort even after making mistakes at any frequency other than not at all like me achieved better scores on the 2019 NAEP reading assessment. The best frequencies, according to the NAEP data, were quite a bit like me, very much like me, and somewhat like me. All of these frequencies had an effect size of large over the frequency of not at all like me. The results align with the research about students who have a growth mindset (Elliott and Dweck (1988)). Students with a growth mindset, incremental theorists, believe that intelligence is a changeable state and when they fail or make mistakes they learn from the failures and mistakes and try harder. Students with a fixed mindset, entity theorists, avoid learning activities that they believe would cause them to make a lot of errors or disconnect from activities when they make errors (Mangels et al. (2006)).

In their research, Mangels et al. found that when students, who were identified as being entity theorists, received negative feedback it caused the students to not remember information presented and that the students demonstrated less effort on the learning task. From this and prior research about growth mindset, it would appear that students with a growth mindset would score higher on the NAEP reading assessments. Based on this, it could benefit school districts to teach students and teachers how to have a growth mindset.

\section{Keep Working Hard Even When I Feel Like Quitting}

This research found that students who responded that they keep working hard even when they feel like quitting at any frequency other than not at all like me 
achieved better scores on the 2019 NAEP reading assessment. The best frequency was quite a bit like me which had a large effect size over the frequency of not at all like me. The frequency of very much like me had a medium effect size over the frequency of not at all like me. Teaching students to have a growth mindset includes teaching students to have grit. Grit is defined as approaching long-term goals with passion and perseverance and maintaining those attributes even when a failure occurs and when some would feel like quitting (Duckworth et al. (2007)). Duckworth et al. (2007) reviewed several studies relating to intelligence and grit and found that individuals with more grit succeeded significantly more than those with less grit even though both groups' IQ scores were similar. Growth mindset and grit coincide by teaching students to appreciate the effort it takes to reach goals and to not quit when faced with challenges (Hochanadel and Finamore (2015)). Students demonstrating grit seemed to score better on the 2019 NAEP reading assessment which again shows the benefit of schools teaching students to have a growth mindset.

\section{Paid Attention and Resisted Distractions}

This study found that students who responded that they paid attention and resisted distractions at any frequency other than never or hardly ever achieved better scores on the 2019 NAEP reading assessment. The best frequencies were more than half the time and all or most of the time. Both of these frequencies had a large effect size over the frequency of never or hardly ever. Teaching mindfulness to students has been shown to improve their attention skills and ability to resist distractions. Morrison et al. (2014) researched a 7-week mindfulness program based on MBSR (mindfulness-based stress reduction) and its effect on students' mind wandering and performance on SARTs (sustained attention to response tasks). The authors found those who practiced mindfulness improved their mind wandering based on self-reports and scores on the SARTs compared to a control group.

This study (Morrison et al. (2014)) as well as the studies by Schonert-Reichl et al. (2015) and Lee (2008) showed the positive impact the use of a mindfulness program can have on students' attention skills. The data from the NAEP 2019 reading assessments showed that students who reported that they paid attention and resisted distractions even less than half of the time showed improvements in their reading scores than students who reported they never or hardly ever paid attention and resisted distractions. These results demonstrate that it could be beneficial to teach students how to improve their attention skills and resist distractions which can be achieved through the use of mindfulness programs in schools.

\section{Felt Happy at School}

The results from this study found that students who responded that they felt happy at school at any frequency other than never or hardly at all scored better on the 2019 NAEP reading assessment. The frequency more than half of the time had a medium effect size over never or hardly at all and less than half the time. Mindwandering is believed to cause people to be unhappy. Killingsworth and Gilbert (2010) found that people's minds wandered away from their present moment task around $46 \%$ of the time. When people thought about pleasant things, they were no happier than when they would focus on their present moment task. When people's minds wandered to neutral or unpleasant thoughts, they were considerably less happy than when they focused on their present moment task. Mindfulness teaches 
people to purposefully pay attention to the present moment without judgment (Kabat-Zinn (2005)).

In 2013, Mrazek et al. researched the use of a two-week mindfulness program that used techniques that taught focused-attention meditation. The results of the study indicated that, compared to a control group that participated in a nutrition program, the students who participated in the mindfulness program reduced their mind wandering and improved their reading and working memory scores on a standardized test.

In addition to reducing mind wandering to improve happiness, teaching selfcompassion to students can also improve happiness. In a non-meditating population, Hollis-Walker and Colosimo (2011) found that individuals with higher mindfulness scores also demonstrated higher self-compassion and psychological well-being. When correlating the scores, higher self-compassion scores were a contributing factor to increasing the mindfulness-happiness relations. Selfcompassion is a skill frequently included in mindfulness lessons so if students have low self-compassion skills these skills can be taught.

These studies (Hollis-Walker and Colosimo (2011) and Mrazek et al. (2013)) demonstrated the ways to improve happiness in students by reducing mind wandering and improving mindfulness and self-compassion skills. The data from the 2019 NAEP reading assessment reported that students who said they felt happy at school more than half of the time scored higher on the reading assessments. Based on these scores, it is recommended that schools use programs, such as teaching mindfulness, to improve students' happiness at school.

In the four research questions studied, the use of a program that teaches growth mindset or mindfulness was recommended to improve students' reading skills. The use of a positive education model such as The PROSPER framework, defined in the literature review, (Noble and Mcgrath (2015)) could help to improve reading scores since it includes teaching growth mindset and mindfulness as well as SEL and identifying character strengths. Using a positive education model could help schools to improve the noncognitive skills reported on by Farrington et al. (2002). Noncognitive skills interact with academic skills and content knowledge to improve students' ability to learn. Without the interaction of all three areas, the ability to learn is decreased. Specifically, the use of a positive education model could help schools to improve students' efforts after making a mistake, continue working hard even when they feel like quitting, increase attention and resist distractions, and increase their happiness at school which could lead to higher reading scores on assessments.

\section{CONCLUSIONS}

This study explored the 2019 NAEP student reading achievement scores for 4 th-grade students and how different areas of affective disposition impacted those scores. Those areas included if students made a great effort after making a mistake, if students worked hard even when they felt like quitting, if students paid attention and resisted distractions, and if students felt happy at school. The results of this study indicated that these areas of students' affective disposition did have an impact on their reading scores.

Students who responded "quite a bit like me" to the statements that they made a great effort even after making mistakes and that they kept working hard even when they feel like quitting achieved significantly higher scores on the 2019 NAEP reading assessment over students who responded not at all like me. Both of these skills can be related to the type of mindset that students have. When students have 
a growth mindset, they do not let mistakes affect how much effort they continue to put into a task, and they continue to work on a skill or a task even if they want to stop (Elliott and Dweck (1988)). Mindset skills may be skills that students already possess when they start school or the skills can be taught to students in school to improve their noncognitive skills (Farrington et al. (2012)) which help students learn.

Students who responded that they paid attention and resisted distractions more than half of the time achieved significantly higher scores on the 2019 NAEP reading assessment over students who responded not at all like me. Attention is a skill that students can be taught. Mindfulness has been shown to improve attention skills in students (Chambers et al. (2007); Lee, 2018; Morrison et al. (2014); and Schonert-Reichl et al. (2015)). While the effect size was not as large as the previous areas, students who felt happy at school more than half the time scored higher on the 2019 NAEP reading assessment over students who reported never or hardly at all and less than half the time. Happiness may be related to how well students are able to pay attention since a study found that when mind wandering occurs, people are unhappy (Killingsworth and Gilbert (2010)). Happiness may also be affected by people's ability to have compassion for themselves (Hollis-Walker and Colosimo (2011)). Reducing mind wandering and increasing self-compassion are skills that can be taught through a mindfulness program (Ackerman (2018); Bishop et al. (2004); andFredrickson (2009)).

Based on the information provided in this study, school districts should consider putting programs in place that impact students' well-being skills such as teaching growth mindset or mindfulness. Adopting a positive education model would address multiple areas of students' well-being including growth mindset and mindfulness. The data analyzed in this study showed that students who demonstrated more positive mindsets about work, better attention skills, and felt happier at school had higher scores on the 2019 NAEP reading assessments.

If school districts as a whole are not able or willing to adopt any of these programs, administrators and teachers are able to make these changes at their school and classroom levels. Administrators can provide training to staff in their schools about growth mindset and mindfulness. This training could be completed in faculty meetings or book studies. Teachers can choose to learn about growth mindset on their own. The book The Growth Mindset Coach by Brock and Hundley (2016) provides monthly lessons that teachers can use to teach their students about having a growth mindset. The book provides background information about what it means to have a growth mindset for both teachers and students, activities to do with students of all ages, and reflection activities for teachers to complete.

Training in mindfulness can also be completed at the building or teacher level. Administrators and teachers can participate in training where they learn how to practice mindfulness themselves and then learn how to teach it to their students. Mindful Schools offers courses to all school staff that provides background information on mindfulness, mindfulness practices, and a secular curriculum with lessons to teach mindfulness to elementary and middle, and high school students (Our Approach. Mindful Schools (2021)). Mindfulness apps are another way that teachers can learn about and establish a mindfulness practice. Both of the apps Smiling Mind (Smiling Mind (2020)) and Calm (Calm (2021)) offer mindfulness practices that can be completed with children.

\section{Limitations to this Study}

There are several limitations in this research study. This data was collected

from a secondary source, NAEP, and if any potential validity problems exist these 
problems would be present in this study. A cause-and-effect relationship should not be explained by the data collected since the variables were pre-selected. The results reported are based on the national scores not on individual student scores and the exact number of students tested is unknown which hinders the validity of this study's results (NCES (2018)). Finally, the analysis methods were based on the models in NAEP and are, therefore, limited.

\section{Recommendations for Future Research}

Since students' well-being skills could be impacted by many factors, it is important to determine what factors are having a positive impact on students' wellbeing and academics. Reading scores in schools that are teaching growth mindset or mindfulness, or using a positive education model could be compared to each other and to schools not implementing these programs. This comparison could help to determine what programs are having the biggest impact on students' well-being and academics. NAEP could add demographic questions to understand if any of these programs are being implemented in the schools they are testing and use this information as a variable for comparing reading scores. Since factors that affect well-being are also learned outside of school, through family, or through programs such as scouting, researching what students are learning outside of school may also be beneficial as a future research study.

\section{REFERENCES}

About The Nation's Report Card: NAEP (2020). About The Nation's Report Card | NAEP. 1. Retrieved from https://nces.ed.gov/nationsreportcard/about/.

Ackerman, C. E. (2018, June 12). Mindfulness in Education: 31+ Ways of Teaching Mindfulness in Schools. PositivePsychology.com. Retrieved from https://positivepsychology.com/mindfulness-education/.

Becker, L. A. (2000, March 20). Effect Size Calculators. Retrieved from http://www.uccs.edu/ lbecker/

Bishop, S. R., Lau, M., Shapiro, S. L., Carlson, L., Anderson, N. D., Carmody, J., \& Devins, G. (2004). Mindfulness: a proposed operational definition. Clinical Psychology: Science and Practice, 11, 230-241. Retrieved from https://doi.org/10.1093/clipsy.bph077

Bond, J., \& Zhang, M. (2017). The Impact of Conversations on Fourth Grade Reading Performance - What NAEP Data Explorer Tells?. European Journal of Educational Research, 6(4), 407-417. doi:10.12973/eu-jer.6.4.407 Retrieved from https://doi.org/10.12973/eu-jer.6.4.407

Brock, A., \& Hundley, H. (2016). The growth mindset coach: A teacher's month-bymonth handbook for empowering students to achieve. Berkeley, CA: Ulysses Press.

Beauchemin, J., Hutchins, T. L., \& Patterson, F. (2008). Mindfulness meditation may

lessen anxiety, promote social skills, and improve academic performance among adolescents with learning disabilities. Complementary Health Practice Review, 13(1), 34-45. doi:10.1177/1533210107311624 Retrieved from https://doi.org/10.1177/1533210107311624

Calm. (2021). Retrieved from https://app.www.calm.com/meditate.

Clark, C., \& Teravainen-Goff, A. (2018). Mental wellbeing, reading and writing How children and young people's mental wellbeing is related to their reading and writing experiences. National Literacy Trust. 
Chambers, R., Lo, B. C. Y., \& Allen, N. B. (2007). The Impact of Intensive Mindfulness Training on Attentional Control, Cognitive Style, and Affect. Cognitive Therapy and Research, 32(3), 303-322. doi: 10.1007/s10608-007-9119-0 Retrieved from https://doi.org/10.1007/s10608-007-9119-0

Cohen, J. (1988). Statistical power analysis for the behavioral sciences (2nd ed.). Hillsdale, NJ: Lawrence Erlbaum.

Creswell, J. W., \& Guetterman, T. C. (2019). Educational research: planning, conducting, and evaluating quantitative and qualitative research. Pearson.

Duckworth, A. L., Peterson, C., Matthews, M. D., \& Kelly, D. R. (2007). Grit: Perseverance and passion for long-term goals. Journal of Personality and Social Psychology, 92(6), 1087-1101. Retrieved from https://doi.org/10.1037/0022-3514.92.6.1087

Donahue, P. L., Daane, M. C., \& Grigg, W. C. (2004). The Nation's Report Card: Reading Highlights 2003. PsycEXTRA Dataset, 5(4), 40-53. https://doi.org/10.1037/e609922011-007 Dweck, C. (2006). Mindset: The new psychology of success. New York: Ballatine Books. Retrieved from https://doi.org/10.1037/e609922011-007

Dweck, C. S. (1986). Motivational processes affecting learning. American Psychologist, 41(10), 1040-1048. doi:10.1037/0003-066x.41.10.1040 Retrieved from https://doi.org/10.1037/0003-066X.41.10.1040

Dweck, C. (2006). Mindset: The new psychology of success. New York: Ballatine Books.

Elliott, E. S., \& Dweck, C. S. (1988). Goals: An approach to motivation and achievement. Journal of Personality and Social Psychology, 54(1), 5-12. Retrieved from https://doi.org/10.1037/0022-3514.54.1.5

Farrington, C.A., Roderick, M., Allensworth, E., Nagaoka, J., Keyes, T.S., Johnson, D.W., \& Beechum, N.O. (2012). Teaching adolescents to become learners. The role of noncognitive factors in shaping school performance: A critical literature review. Chicago: University of Chicago Consortium on Chicago School Research.

Fredrickson, B. (2009). Positivity. New York: Crown Publishing Group.

Hochanadel, A., \& Finamore, D. (2015). Fixed And Growth Mindset In Education And How Grit Helps Students Persist In The Face Of Adversity. Journal of International Education Research (JIER), 11(1), 47-50. Retrieved from https://doi.org/10.19030/jier.v11i1.9099

Hjeltnes, A., Binder, P., Moltu, C \& Dundas, I. (2015) Facing the fear of failure: An explorative qualitative study of client experiences in a mindfulness-based stress reduction program for university students with academic evaluation anxiety, International Journal of Qualitative Studies on Health and Wellbeing, 10:1, 27990, DOI: 10.3402/qhw.v10.27990 Retrieved from https://doi.org/10.3402/qhw.v10.27990

Hollis-Walker, L., \& Colosimo, K. (2011). Mindfulness, self-compassion, and happiness in non-meditators: A theoretical and empirical examination. Personality and Individual Differences, 50(2), 222-227. Retrieved from https://doi.org/10.1016/j.paid.2010.09.033

Kabat-Zinn, J. (2005). Wherever you go, there you are: mindfulness meditation in everyday life. New York: Hachette Books. 
Killingsworth, M. A., and Gilbert, D. T. (2010). A wandering mind is an unhappy mind. Science 330, 932. doi: 10.1126/science.1192439 Retrieved from https://doi.org/10.1126/science.1192439

Klecker, B. M. (2014, November 5). NAEP fourth-, eighth-, and twelfth-grade reading scores by gender: 2005, 2007, 2009, 2011, 2013. Paper presented at the annual meeting of the Mid-South Educational Research Association Knoxville, TN.

Lee, J., Semple, R. J., Rosa, D., \& Miller, L. (2008). Mindfulness-based cognitive therapy for children: results of a pilot study. Journal of Cognitive Psychotherapy, 22, 15-28. doi:10.1891/ 0889.8391.22.1.15. Retrieved from https://doi.org/10.1891/0889.8391.22.1.15

Mangels, J. A., Butterfield, B., Lamb, J., Good, C., \& Dweck, C. S. (2006). Why do beliefs about intelligence influence learning success? A social cognitive neuroscience model. Social Cognitive and Affective Neuroscience, 1(2), 7586. Retrieved from https://doi.org/10.1093/scan/nsl013

Mcleod, S. (2019, July 10). Effect Size. Simply Psychology. Retrieved from https://www.simplypsychology.org/effect-size.html.

Morrison, A. B., Goolsarran, M., Rogers, S. L., \& Jha, A. P. (2014). Taming a wandering attention: short-form mindfulness training in student cohorts. Frontiers in Human Neuroscience, $7 . \quad$ Retrieved from https://doi.org/10.3389/fnhum.2013.00897

Mrazek, M. D., Franklin, M. S., Phillips, D. T., Baird, B., and Schooler, J. W. (2013). Mindfulness training improves working memory capacity and GRE performance while reducing mind wandering. Psychol. Sci. 24, 776-781. doi: 10.1177/0956797612459659 Retrieved from https://doi.org/10.1177/0956797612459659

NAEP - Sample Design. (2018, July 17). Retrieved from Retrieved from https://nces.ed.gov/nationsreportcard/tdw/sample_design/

NCES. (2020). About The Nation's Report Card: NAEP. About The Nation's Report \begin{tabular}{l|lll} 
Card & NAEP. & Retrieved
\end{tabular} https://nces.ed.gov/nationsreportcard/about/.

NCES. (2021a) Reading Assessment. NAEP reading. Retrieved from https://nces.ed.gov/nationsreportcard/reading/.

NCES. (2021b). NDE Core Web. The Nation's Report Card. Retrieved from https://www.nationsreportcard.gov/ndecore/xplore/nde.

NCES. (2018). Select the Participants - Assessment Process: NAEP. Assessment \begin{tabular}{l|lll} 
Pneffrocess & NAEP.
\end{tabular} https://nces.ed.gov/nationsreportcard/assessment_process/selection.asp $\mathrm{x}$.

Neff, K. (2003). Self-Compassion: An Alternative Conceptualization of a Healthy Attitude Toward Oneself. Self and Identity, 2(2), 85-101. doi:10.1080/15298860309032 Retrieved from https://doi.org/10.1080/15298860309032

Noble, T., \& Mcgrath, H. (2015). PROSPER: A New Framework for Positive Education. Psychology of Well-Being, 5(1). doi:10.1186/s13612-015-0030-2 Retrieved from https://doi.org/10.1186/s13612-015-0030-2 
Norrish, J. M., Williams, P., O'Connor, M., \& Robinson, J. (2013). An applied framework for positive education. International Journal of Wellbeing, 3(2), 147-161. doi:10.5502/ijw.v3i2.2

Our Approach. Mindful Schools. (2021, March 23). Retrieved from https://www.mindfulschools.org/our-approach/.

Parhiala, P., Torppa, M., Vasalampi, K., Eklund, K., Poikkeus, A.-M., \& Aro, T. (2018). Profiles of school motivation and emotional well-being among adolescents: Associations with math and reading performance. Learning and Individual Differences, 61, 196-204. doi:10.1016/j.lindif.2017.12.003 Retrieved from https://doi.org/10.1016/j.lindif.2017.12.003

Schonert-Reichl, K. A., Oberle, E., Lawlor, M. S., Abbott, D., Thomson, K., Oberlander, T. F., \& Diamond, A. (2015). Enhancing cognitive and social-emotional development through a simple-to-administer mindfulness-based school program for elementary school children: A randomized controlled trial. Developmental Psychology, 51(1), 52-66. Retrieved from https://doi.org/10.1037/a0038454

Siegel, D. J. (2016). Mind: A journey to the heart of being human. New York: WW Norton \& Company. Retrieved from https://doi.org/10.1093/mind/fzv114

Smiling Mind. (2020). Retrieved from https://www.smilingmind.com.au/. 